\title{
Prognosis
}

\section{Positive family interaction was associated with fewer relapses in patients admitted to hospital for psychotic disorder}

Halford WK, Steindl S, Varghese FN, et al. Observed family interaction and outcome in patients with first-admission psychoses. Behavior Therapy 1999 Winter/Fall;30:555-80.

QUESTION: In patients who are admitted to hospital for the first time with a psychotic disorder, does family interaction assessed at the time of admission help to predict patient outcome at 6 months?

\section{Design}

Inception cohort with 6 months of follow up after first hospital admission.

\section{Setting}

Psychiatric units of 2 large hospitals in Brisbane, Queensland, Australia.

\section{Patients}

52 families in which 1 member was a patient (mean age $31 \mathrm{y}, 60 \%$ men) who had a first psychiatric inpatient admission; met DSM-III-R criteria for a schizophrenic disorder $(31 \%)$ or an affective disorder with psychotic features (69\%); and lived with a parent, sibling, or spouse for $\geq 1$ of the 3 months before admission and $\geq 2$ months after discharge; and whose family lived within $50 \mathrm{~km}$ of Brisbane.

\section{Assessment of prognostic factors}

Family interaction was assessed at 7-10 days in a 10 minute interaction between the patient and a relative who was nominated by the patient and with whom the patient was living. The interaction was videotaped and later coded using the Interactional Coding System. This method involved analysing responses and categorising them as positive (self disclosure, acceptance, positive solution, acceptance, agreement, or listening with positive non-verbal responses); neutral (description, metacommunication, and listening with neutral non-verbal responses); or negative (criticism, negative solution, disagreement, justification, or listening with negative nonverbal responses). Families were classified as affect regulated (cumulative affect is positive for both participants) or affect unregulated (cumulative affect is neutral or negative for either patient or relative). Patients were also assessed with the Brief Psychiatric Rating Scale (BPRS) and the Premorbid Adjustment Scale.

\section{Main outcome measures}

Psychotic relapse (score of 6 or 7 on BPRS items for hallucinations, delusions, and disorganised thinking; increase in antipsychotic medication for exacerbation of psychotic symptoms; or readmission for a psychotic episode). Severity of psychopathology, global functioning, and quality of life were also assessed but these outcomes had

Source of funding: none stated.

For correspondence:

Professor W K Halford,

School of Applied

Psychology, Griffith

University, Nathan,

Oueensland 4111,

Australia.Fax +617

38753399 .

\section{$<80 \%$ follow up.}

\section{Main results}

Patients from affect regulated families had lower relapse rates at 6 months than those from affect unregulated families $(15 \%$ v $50 \%, \mathrm{p}<0.05)$. Relapse rate was not associated with diagnosis or rates of negative and positive behaviour. A logistic regression that included diagnosis, affect regulation, and the interaction between diagnosis and affect regulation showed that affect regulation improved prediction of relapse.

\section{Conclusion}

In patients admitted for the first time to a hospital for a psychotic disorder, positive family interaction was associated with fewer relapses at 6 months.

\section{COMMENTARY}

The study by Halford $e t$ al shows the importance of family interactions for the course and outcome of psychotic disorders. The mechanisms through which family interactions may influence course and outcome are poorly understood. Research has almost exclusively used the paradigm of expressed emotion (EE) to explore this relation. Halford et al have provided a concise and critical review of the limitations inherent in the EE approach. The greatest limitation of the $\mathrm{EE}$ approach is the lack of a clinically useful method for assessing EE status and the multidimensional nature of outcome in patients with psychotic disorders. In this study, unlike the EE model, the emphasis is not on negative interactions alone. The "affect regulation" model takes into consideration that positive social support is associated with better outcome in all psychiatric disorders.

The results show that patients living in affect regulated families had a lower relapse rate. Although the interaction of diagnosis and affect regulation did not predict outcome, it is notable that most patients with schizophrenia lived in families that were classified as affect unregulated (ie, exposed to neutral affect or negative affect). This may reflect either a more severe and/or prolonged effect of schizophrenia on family relationships or a reduced capacity of these families to regulate their affect positively. Results show a rather high rate of relapse or readmission to hospital for all first episode psychosis. The exact nature of treatment is unclear.

The authors' approach involved an assessment of 2-way interaction between the patient and family member, unlike the EE assessment. ${ }^{12}$ If this approach can predict outcome in a larger sample, there are 2 distinct implications: (1) affect regulation may be a clinically useful, brief, and inexpensive method of assessing family interaction; and (2) it may be possible to train family members in positive affect regulation. Further research is required to examine the nature of the relation between illness characteristics and affect regulation, predictive value of this method of assessment, and the feasibility of providing training to families as part of coping strategies.

Ashok Malla, MBBS, FRCP(C)

University of Western Ontario London, Ontario, Canada

1 Magana AB, Goldstein JM, Karno M, et al. A brief method for assessing expressed emotion in relatives of psychiatric patients. Psychiatry Res 1986;17:203-12.

2 Malla AK, Kazarian SS, Barnes S, et al. Validation of the five minute speech sample in measuring expressed emotion. Can J Psychiatry 1991;36:297-9. 